\title{
Magistério público da EB À luz da reforma do Estado ${ }^{1}$
}

\author{
Adriana Marinho Pimentel ${ }^{*}$ \\ Rosana Maria Gemaque Rolim ${ }^{* *}$
}

\begin{abstract}
RESUMO: O artigo revela que a regulação da carreira do magistério público da educação básica estava inserida no plano de reforma, que por ter seguido o receituário neoliberal, introduziu diferentes mecanismos reguladores, um dos obstáculos para a elaboração de planos de Carreira comprometidos com a valorização docente.
\end{abstract}

Palauras-chave: Regulação. Carreira do magistério público da educação básica. Reforma do Estado.

\section{Introdução}

A

tualmente, a carreira do magistério público da educação básica (EB) no Brasil é regulamentada por um conjunto de leis, aprovadas no âmbito federal, que devem ser observadas pelos gestores e professores vinculados aos diferentes sistemas de ensino ao elaborarem os planos de Carreira do magistério público da educação básica.

O aparato normativo que regulamenta a carreira desse profissional foi introduzido pela reforma do Estado brasileiro, efetivada nos anos de 1990, que desencadeou várias reformas no sistema educativo brasileiro. Por esse motivo, não é possível realizar estudos sobre a carreira do magistério público como um fenômeno isolado, desconsiderando o contexto em que ela foi regulamentada.

* Mestre em Educação. Professora efetiva da Secretaria Estadual de Educação do Pará (Seduc/PA), pedagoga efetiva da Prefeitura Municipal de Oriximiná, integrante do Grupo de Estudo em Gestão e Financiamento da Educação (Gefin/Iced/UFPA) no Programa de Pós-graduação. Oriximina/PA - Brasil. E-mail:<adriorix@hotmail.com>.

** Doutora em Educação. Professora Associada I da Universidade Federal do Pará (UFPA), na graduação e pós-graduação. Participa do corpo editorial das revistas Ver Educação (UFPA), Anped, Anpae e Fineduca. Coordena Grupo de Pesquisa (Gefin) e projetos de pesquisa financiados pelo CNPq (Edital Universal) e Capes (Obeduc). Belém/PA - Brasil. E-mail: <rgemaque@uol.com.br>. 
Este artigo tem como objetivo analisar os mecanismos de regulação da carreira do magistério público da educação básica a partir da reforma do Estado, visando compreender suas implicações na elaboração de planos de Carreira comprometidos com a valorização docente.

Trata-se de um recorte dentre muitas outras discussões que emergiram no desenvolvimento de um estudo sobre a carreira do magistério público da rede municipal de ensino do município de Oriximiná-PA, que analisa a carreira desses profissionais na perspectiva de compreender sua configuração e atratividade.

Para proceder a análise dos mecanismos de regulação da carreira estabelecidos pelo governo federal a partir da reforma, partiu-se do contexto econômico e político em que tal reforma foi efetivada, trazendo na esteira desta discussão as principais alterações na legislação educacional que repercutiram na regulação da carreira desse profissional nosso País.

\section{A reforma do Estado Brasileiro a partir dos anos 1990}

O Estado brasileiro, na atual conjuntura, é produto de um longo processo de mudanças, que se intensificaram principalmente a partir da grande crise capitalista mundial dos anos 1970 e 1980, atingindo os países centrais e os periféricos.

Por volta dos anos 1970, a economia capitalista mundial, liderada pelos Estados Unidos, experimentou sua primeira recessão generalizada desde a Segunda Guerra Mundial. O excesso de produção; a queda da taxa de lucro; a saturação do modelo de produção taylorista/fordista, com as greves dos trabalhadores; a desvalorização do dólar americano, considerado o "padrão ouro" do capitalismo; a crise do "Estado de Bem-Estar Social" $^{2}$ e a crise do Petróleo constituíram um quadro crítico do modelo econômico do pós-guerra. Com isso, "todo o mundo capitalista avançado caiu numa longa e profunda recessão, combinando pela primeira vez, baixas taxas de crescimento com altas taxas de inflação." (ANDERSON, 1998, p. 10).

Foi neste contexto que, segundo Anderson (1998), as ideias neoliberais passaram a ganhar força. Para o autor, o neoliberalismo foi uma reação teórica e política veemente contra o Estado intervencionista e de bem-estar. Isso porque, para os neoliberais, as raízes da crise mundial do capitalismo

estavam localizadas no poder excessivo e nefasto dos sindicatos e, de maneira mais geral, do movimento operário que havia corroído as bases de acumulação capitalista com suas pressões reivindicativas sobre o salário e com sua pressão parasitária para que o Estado aumentasse cada vez mais os gastos sociais. Esses dois processos destruíram os níveis necessários de lucros das empresas e desencadearam processos inflacionários que não podiam deixar de terminar numa crise generalizada das economias de mercado. O remédio, então era claro: manter 
um Estado forte, sim, em sua capacidade de romper o poder dos sindicatos e no controle do dinheiro, mas parco em todos os gastos sociais e nas intervenções econômica. A estabilidade monetária deveria ser a meta suprema de qualquer governo. Para isso seria necessária uma disciplina orçamentária, com a contenção dos gastos com bem- estar, e a restauração da taxa "natural" de desemprego, ou seja, a criação de um exército de reserva de trabalho para quebrar o sindicato. Ademais, reformas fiscais eram imprescindíveis, para incentivar os agentes econômicos [...] (ANDERSON, 1998, p. 11).

Como fica evidente, no receituário neoliberal, o Estado deveria reduzir ao máximo seus gastos com o social e intervir o mínimo possível na economia, garantido o livre fluxo do capital, sempre priorizando a estabilidade monetária. A concepção neoliberal para a superação da crise econômica do período em questão se alastrou nos países de capitalismo avançado e na periferia capitalista latino-americana. $\mathrm{O}$ receituário neoliberal foi sendo modelado de acordo com os objetivos dos governos, mas a reestruturação do Estado sempre se apresentava como a principal preocupação.

No Brasil, a estratégia neoliberal por meio da qual se pretendia tirar o País da crise econômico-financeira e elevá-lo aos patamares dos países do primeiro mundo ganhou força no início dos anos 1990, quando o governo brasileiro, seguindo orientações de países desenvolvidos e de instituições financeiras internacionais (Banco Mundial e Fundo Monetário Internacional), passa a executar "uma drástica redefinição da agenda pública, atribuindo prioridade absoluta ao binômio estabilização econômica e reformas estruturais." (DINIZ, 2011, p. 498).

Para conduzir o processo de reforma neoliberal do Estado brasileiro foi criado, no governo de Fernando Henrique Cardoso (FHC), o extinto Ministério da Administração e Reforma do Estado (Mare), tendo como ministro, de1995 a 1998, Luiz Carlos Bresser Pereira, o qual foi elaborador do Plano Diretor da Reforma do Aparelho do Estado (1995).

Nesse documento, Bresser-Pereira (1995) propõe uma ampla reforma administrativa que iria exigir mudanças na legislação brasileira. Na remuneração e carreira dos servidores públicos, o autor chamou atenção para a importância de o sistema de motivação dos servidores públicos brasileiros ser repensada. Nesses termos, a profissionalização do servidor público ocorreria não apenas pelo acesso via concursos e processos seletivos públicos, mas, sobretudo, por meio de um sistema de promoções na carreira em função do mérito. Além dessa ideia, também foi expressa uma espécie de "motivação negativa", que consistiria na demissão do servidor público por insuficiência de desempenho. Sem essa "motivação negativa", no seu entendimento, seria impossível levar o funcionário comum a valorizar seu emprego.

Foi com base nesses argumentos que o governo de Fernando Henrique Cardoso, ainda no primeiro mandato, aprovou duas importantes emendas constitucionais, que atingiram diretamente os servidores públicos, incluindo os professores: a ECnํ19, de 1998 (que modifica o regime e dispõe sobre princípios e normas da administração pública, servidores e 
agentes políticos, controle de despesas e finanças públicas e custeio de atividades a cargo do Distrito Federal) e a EC nº 20, de 1998 (que modifica o sistema de previdência social e estabelece normas de transição).

A EC nº 19, de 1998 introduziu modificações significativas com rebatimentos na carreira e remuneração, dentre elas a exclusão do princípio de isonomia de vencimentos e inclusão do regime de subsídio para algumas categorias de agentes públicos; o aumento do período de estágio probatório de dois para três anos; as alterações no sentido do conceito de estabilidade do servidor, incluindo a possibilidade de perda de cargo pelo servidor estável pautada na insuficiência de desempenho e quando houvesse necessidade de diminuir as despesas com o pagamento de pessoal ativo e inativo que ultrapassasse os limites fixados na Lei Complementar no 1996/1999³.

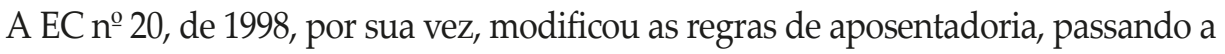
vincular tempo de contribuição à idade mínima para aposentadoria. No caso dos servidores públicos incorporados ao Regime Geral de Previdência, a aposentadoria passou a ser assegurada desde que comprovados sessenta anos de idade e trinta e cinco anos de contribuição, se homem, e cinquenta e cinco anos de idade e trinta anos de contribuição, se mulher ${ }^{4}$. Contudo, manteve a aposentadoria especial para os professores da educação básica, garantido a redução de cinco anos, em relação aos demais trabalhadores, do tempo de contribuição e de idade.

Como é possível observar, as modificações introduzidas por estas duas emendas constitucionais foram direcionadas para a redução de custos com o pagamento do pessoal ativo e inativo, revelando a redefinição do papel do Estado aos moldes da lógica neoliberal. Além dessas modificações na Constituição Federal de 1988, a reforma demandou ainda a implementação de diferentes políticas públicas, inclusive na área da educação, dentre as quais algumas direcionadas à regulação da carreira do magistério público da educação básica.

\section{A regulação da carreira do magistério público da educação básica}

Ao analisar visões e perspectivas de diferentes teóricos que discutem o papel do Estado, Picanço (2012) ressalta que "regular" a vida em sociedade é inerente à função do Estado, que este estabelece regras, cria e implementa políticas e atua para corrigir falhas ou déficits na oferta dos serviços público ou para atingir objetivos.

Contudo, frisa o autor, modelos de Estado apresentam, por sua vez, diferentes formas de regulação na área econômica e social. No modelo defendido pelos neoliberais, o Estado deveria intervir o menos possível na atividade econômica para dar espaço à livre atuação e regulação do mercado, assim como reduzir sua atuação na oferta dos diferentes serviços públicos. Nessa perspectiva, o Estado passa a ser muito mais indutor e regulador do que promotor ou provedor das política sociais. 
Ao aderir a esse modelo de Estado, o governo brasileiro, por meio da execução do Plano de Reforma na área da educação, focou sua atuação na regulação financeira, por meio da qual passou a operacionalizar um conjunto de planos setoriais, legislação e financiamento, por meio de Fundos.

De acordo com Espíndola (2002), o ato normativo (promulgação de leis, decretos e resoluções) é o instrumento, por excelência, de regulação do Estado e é por meio do qual, por exemplo, se define carreira docente e sua estrutura salarial.

São esses atos normativos emanados do Governo Federal que denominamos de mecanismos de regulação da carreira do magistério público da educação básica no Brasil. Para analisá-los partiremos da CF de 1988 e adentraremos ao conjunto das leis e resolução que atualmente definem as diretrizes da carreira do magistério público.

Inicialmente, cabe observar que a CF de 1988, em virtude do intenso processo de mobilização da sociedade pela garantia de diversos direitos, apresenta um extenso capítulo destinado à educação, no qual a valorização dos profissionais do ensino apresenta-se como um dos princípios constitucionais (inciso V do art. 206).

A inserção desse princípio constitucional, na concepção de Dutra Júnior et al. (2000), significou o reconhecimento, por parte de amplos setores da sociedade brasileira, da baixa qualidade da escola pública e da desvalorização profissional vivenciada pelos professores. Além disso, segundo Vieira (2013), a CF de 1988 avança por ser a primeira a propor Piso Salarial Profissional Nacional como uma das condições para promover a valorização dos profissionais do ensino. Apesar disso, todas as condições necessárias para a garantia do princípio de valorização, inscritas no inciso V do art. 206, ficaram na dependência de legislação reguladora.

Com a emergência das políticas de orientação neoliberal, deu-se início a uma série de reformas no setor educacional. Como parte da reforma, é aprovada a EC nº 14, de 1996, proposta pelo então presidente FHC, juntamente com seu ministro da Educação, Paulo Renato de Souza, que criou o Fundo de Manutenção e Desenvolvimento do Ensino Fundamental e de Valorização do Magistério (Fundef), para vigorar por dez anos. O Fundef era um Fundo de natureza contábil ${ }^{5}$, constituído no âmbito estadual e do Distrito Federal, para canalizar recursos exclusivamente para o ensino fundamental público e para a valorização dos profissionais do magistério que atuavam nesta etapa da educação.

Antes da regulamentação do Fundef, foi ainda aprovada a LDB no 9.394, de 1996, que deixou a elaboração de políticas de valorização do magistério sob a responsabilidade dos diferentes sistemas de ensino.

Eis o artigo da referida lei que versa sobre essa responsabilidade:

Art. 67. Os sistemas de ensino promoverão a valorização dos profissionais da educação, assegurando-lhes, inclusive nos termos dos estatutos e dos planos de carreira do magistério público:

I - ingresso exclusivamente por concurso público de provas e títulos; 


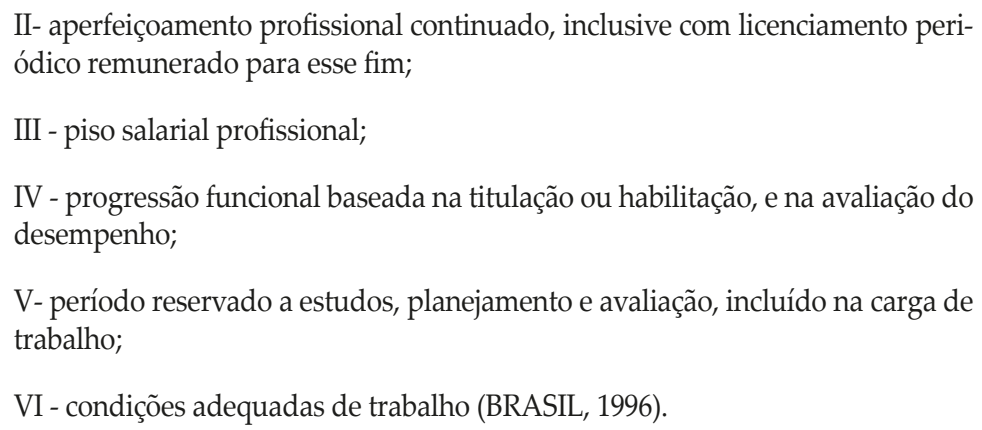

Isto posto, fica evidente que os mecanismos de valorização dos profissionais da educação, inscritos nos incisos do art. 67 da LDB nº 9.394, de 1996, devem ser assegurados nos Estatutos e Planos de Carreira do magistério público.

Para Dutra Júnior et al. (2000) o Estatuto é uma espécie de lei ampla, que deve dispor sobre investidura na carreira, direitos e deveres do profissional, responsabilidades, dentre outros. O Plano de Carreira, por sua vez, deve tratar de normatizações mais específicas acerca da carreira profissional, como, por exemplo, a progressão funcional e a evolução da remuneração. De toda forma, em virtude das determinações da LDB $n^{0}$ 9.394, de 1996, o que deveria ser revisto imediatamente pelos entes federados era o Plano de Carreira e não o Estatuto. Este último poderia ser alterado, mas como decorrência da reforma administrativa, introduzida pela EC nํ19, de 1998 (DUTRA JÚNIOR et al., 2000).

Alguns dias depois da aprovação da LDB nº 9.394, de 1996, o Fundef foi regulamentado pela Lei no 9.424, de 1996. Sua finalidade, de acordo com Gemaque (2013, p. 7), era "estimular a municipalização do ensino, uma vez que redistribuía recursos, no âmbito dos Estados, de acordo com o número de alunos matriculados no ensino fundamental, a partir da razão entre o valor mínimo por aluno-ano e a receita do Fundo". O valor a ser aplicado por aluno era definido e divulgado anualmente pelo Governo Federal que, naqueles casos em que o estado não alcançasse tal valor, complementaria os recursos, de modo a garantir o mínimo definido nacionalmente.

No que tange aos professores, a Lei n 9.424, de 1996 (Fundef), estabeleceu que pelo menos $60 \%$ dos recursos do Fundo deveriam ser aplicados no pagamento dos profissionais do magistério efetivamente em exercício. Todavia, Lei não dispôs especificamente sobre o valor da remuneração que deveria ser paga, limitou-se a tratar dessa questão de forma subjetiva, quando no art. 9ำ assegurou aos professores "remuneração condigna", deixando para os estados e municípios a responsabilidade de definir essa remuneração nos planos de Carreira.

Em meio às inúmeras críticas ao Fundef, destacamos as considerações feitas por Saviani (2011) 
[...] essas medidas (implementadas pelo FUNDEF) tinham o objetivo meritório de distribuir melhor os recursos tendo em vista o financiamento do ensino fundamental, elas se limitaram, no entanto, a regular a aplicação de recursos e, além disso, reduzindo a participação financeira da União através da Emenda ao artigo 60 das Disposições Constitucionais Transitórias. Como resultado, o custo mínimo por aluno foi fixado em $R \$ 300,00$ (trezentos reais), cifra irrisória comparada com os valores praticados pelos países que lograram generalizar o acesso e a permanência no ensino fundamental. Trata-se, assim, de um patamar que consagra o estado de miséria da educação nacional, evidenciando a precária vontade política do governo no enfrentamento dessa questão (SAVIANI, 2011, p. 36).

Diante disso considera-se que o Fundef se apresenta como um mecanismo que regulamentou tanto o atendimento às matriculadas - visto que contribuiu para desencadear um processo acelerado de municipalização - quanto a aplicação de parte dos recursos destinados à educação, focalizando-a numa etapa da educação básica (o ensino fundamental) e reservando uma parcela para a remuneração de professores. (GEMAQUE, 2004; PICANÇO, 2012).

Assim, os problemas identificados no Fundef fizeram com que, ainda nos anos 1990, surgisse a proposta de constituição de um novo Fundo, destinado a financiar todas as etapas e modalidades da educação básica. A tramitação da proposta, segundo Oliveira (2007), foi lenta, em virtude da oposição do governo FHC à sua concepção, e da oposição da área econômica durante o primeiro mandato do presidente Luiz Inácio Lula da Silva, adepta dos princípios neoliberais de racionalização do gasto social. Contudo, diante de forte pressão e da necessidade de alterar o Fundef, devido à aproximação do fim da vigência deste Fundo, foi aprovada a EC nํ53, de 2006.

Essa Emenda Constitucional alterou o art. 206 da CF de 1988, reformulando a redação do inciso V e incluindo o inciso VIII no mesmo artigo.

Diz o texto constitucional após as alterações:

Art. 206. O ensino será ministrado com base nos seguintes princípios:

$[\cdots]$

V - valorização dos profissionais da educação escolar, garantidos, na forma da lei, planos de carreira, com ingresso exclusivamente por concurso público de provas e títulos, aos das redes públicas;

\section{$[\ldots]$}

VIII - piso salarial profissional nacional para os profissionais da educação escolar pública, nos termos de lei federal (BRASIL, 1988, grifos nossos).

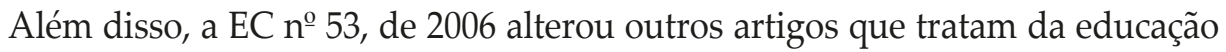
(art. 7º , 23, 30, 211 e 212), o art. 60 do Ato das Disposições Constitucionais Transitórias, criando, finalmente, o Fundo de Manutenção e Desenvolvimento da Educação Básica 
e de Valorização dos Profissionais da Educação (Fundeb), em substituição ao Fundef, e determinou que tanto o Fundeb como o Piso Salarial Profissional Nacional para os profissionais do magistério público da educação básica deveriam ser regulamentados em leis federais específicas.

Regulamentado pela Lei nº 11.494, de 2007, o Fundeb mantém a mesma estratégia de redistribuição de recursos do Fundef. No entanto, trouxe importantes avanços em seu desenho: extensão a todas as matrículas da educação básica; como consequência, também aumentou os recursos financeiros que o compõem, ampliando gradativamente o percentual de vinculação dos impostos de $15 \%$ para $20 \%$, incluindo mais dois impostos em sua composição, o IPVA e o ITCD; ampliação da complementação da União para 10\% da receita total dos fundos; implantação do PSPN, a partir dos recursos do Fundeb, de outros impostos (IR, IPTU,ISSQN e ITBI) e de auxílio emergencial do Ministério da Educação ao ente federado que comprovasse sua incapacidade financeira para o pagamento do piso.

Em relação à remuneração dos profissionais do magistério, o Fundeb mantém a destinação de, pelo menos, $60 \%$ dos recursos do Fundo para o pagamento dos profissionais do magistério em efetivo exercício, contemplando não apenas os que atuavam no ensino fundamental, como acontecia no Fundeb, mas também os que atuavam em todas as etapas da educação básica.

No que tange à implementação de Planos de Carreira e Remuneração dos profissionais da educação básica, a Lei do Fundeb determina:

Art. 40. Os Estados, o Distrito Federal e os Municípios deverão implantar Planos de Carreira e remuneração dos profissionais da educação básica, de modo a assegurar:

I - a remuneração condigna dos profissionais na educação básica da rede pública; II - integração entre o trabalho individual e a proposta pedagógica da escola;

III - a melhoria da qualidade do ensino e da aprendizagem (BRASIL, 2007, grifo nosso).

Com relação a este artigo, a Lei do Fundeb mantém a expressão "remuneração condigna", mas assim como no Fundef, a mesma permanece sem definição, cabendo aos estados, Distrito Federal e municípios a tarefa de interpretá-la nos planos de Carreira. Todavia, a Lei do Fundeb trouxe um aspecto de grande relevância para a melhoria da remuneração dos professores, ao estabelecer no seu art. 41, a obrigatoriedade do poder público de fixar, em lei específica, o Piso Salarial Profissional Nacional (PSPN) para os profissionais do magistério público da educação básica.

Deste modo, o Fundeb apresenta-se como outro mecanismo que também regulamenta a aplicação de parte dos recursos da educação, destinando-os à educação básica no seu todo e reservando uma parte para o pagamento dos professores. Mas, a regulação é ampliada em relação ao Fundef por estabelecer um valor mínimo para o vencimento inicial dos professores. 
Para dar cumprimento aos dispositivos legais constantes na CF de 1988, na EC nํㅜㄹ, de 2006 e na Lei n⿳ำ 11.494, 2007, foi aprovada a Lei $n^{0}$ 11.738, de 2008, que dispôs sobre o Piso Salarial Profissional Nacional (PSPN) para os profissionais do magistério público da educação básica. A Lei fixa o Piso Salarial Profissional Nacional para os professores com formação em nível médio, na modalidade normal; esclarece que os vencimentos iniciais referentes às demais jornadas de trabalho deverão, no mínimo, ser proporcionais ao valor do piso para 40 horas semanais; e estabelece o limite máximo de $2 / 3$ (dois terços) da carga horária do professor para atividades com os alunos, reservando-se assim $1 / 3$ (um terço) dessa carga horária para atividades extraclasse. Além disso, para garantir o pagamento do PSPN, nos casos em que o ente federativo não tenha disponibilidade orçamentária para o seu cumprimento, a lei responsabiliza a União pela complementação dos recursos necessários.

A Lei no 11.738, de 2008 (PSPN), assim como o Fundef e Fundeb, apresenta-se como mais um mecanismo de regulação da carreira do magistério público da educação básica. Na concepção de Vieira (2013), a Lei do Piso, como ficou conhecida, representou um significativo avanço rumo à valorização dos profissionais do magistério público, haja vista que até então "não havia legislação nacional definidora de igualdade salarial para os profissionais da educação pública no Brasil. Cada ente federado - União, estados, municípios e DF - obedecia à sua legislação e às suas regras" (p. 113).

Para orientar a elaboração e implantação dos planos de carreira, conforme determinação da CF de 1988, LDB no 9.394, de 1996, Lei do Fundeb e da Lei do Piso, foi estabelecida a Resolução n⿳ำ 2, de 20096 , do Conselho Nacional de Educação/Câmara da Educação Básica, que dispõe sobre as Novas Diretrizes Nacionais para os Planos de Carreira e Remuneração dos Profissionais do Magistério da Educação Básica Pública.

No que se refere aos critérios para remuneração dos profissionais do magistério, a Resolução nº 2, de 2009, incorpora os preceitos da Lei nº 11.494, de 2007 (Fundeb) e da Lei n⿳o. 11.738, de 2008 (PSPN), no que tange à parcela da verba do Fundo $(60 \%)$ destinada ao pagamento dos profissionais do magistério. Além disso, reafirma o dever dos entes federados, de instituírem planos de Carreira para todos os profissionais do magistério que atuam nas diferentes etapas da educação básica, e, eventualmente, aos demais profissionais da educação; e por fim, apresenta as diretrizes para a adequação dos planos de Carreira aos dispositivos da Lei no 11.494 , de 2007 (Fundeb) e da Lei nº 11.738, de 2008 (PSPN).

O percurso da legislação que regulamenta a carreira do magistério público da educação básica nos permite compreender como a obrigatoriedade da organização da carreira do magistério público foi sendo consolidada nos termos da Lei. No entanto, o fato da legislação específica da educação garantir a organização da carreira docente por meio de planos de Carreira como um dos mecanismos de valorização docente não significa a garantia de sua efetivação na prática. 


\section{Considerações Finais}

A regulação da carreira do magistério público da educação básica, a partir da Reforma do Estado, foi efetivada por meio de um aparato de atos normativos alinhado aos princípios neoliberais que priorizam políticas de ajuste fiscal e de estabilidade econômica. Esses atos normativos são o que denominamos de mecanismos de regulação. Como principais mecanismos de regulação da carreira do magistério público da educação básica destacamos o Fundef, o Fundeb e PSPN. Tais mecanismos trouxeram em seu bojo elementos que apresentam-se como obstáculos para o desenvolvimento da educação no País e para a elaboração de planos de Carreira comprometidos com a valorização docente.

Em relação ao Fundef, houve um repasse de matrículas aos municípios que, por sua vez, assumiram reponsabilidades para além de sua capacidade orçamentária, o que em certos lugares inviabiliza a garantia do acesso de todas as crianças e jovens à escola, compromete a qualidade do ensino e a valorização dos professores; o Fundeb, apesar de ampliar o seu raio de ação, continuou pautado em um valor-aluno aquém do necessário para se garantir a universalização, a qualidade do ensino e a valorização dos professores; e o PSPN parece impactar de diferentes formas: de um lado possibilita elevar a remuneração em locais que o vencimento era muito baixo e de outro tem sido referência para congelar a remuneração ou até mesmo reduzi-la. Além disso, governadores e prefeitos denunciam que seus orçamentos não permitem assegurar o pagamento do PSPN, visto que a União limita sua participação financeira.

Dessa forma, apesar de prometerem a valorização do magistério público, esses mecanismos de regulação configuram-se como exemplos de políticas neoliberais na área da educação, posto que a União assume a função reguladora e atribui aos demais entes federados a responsabilidade pela execução de tais políticas.

Diante desse cenário, concluímos que os escassos recursos disponibilizados pela União à educação básica, e a ausência de ações mais decididas do Governo Federal na redução da desigualdade nos entes federados constitui obstáculo ao desenvolvimento de políticas públicas comprometidas com a valorização dos profissionais do magistério da educação básica.

Recebido em fevereiro de 2016 e aprovado em abril de 2016 


\section{Notas}

1 O estudo contou com o apoio da pesquisa nacional em rede Remuneração de professores de escolas públicas da educação básica no contex to do FUNDEB e do PSPN, financiada pelo Edital N. 049/2012, CAPES/INEP/MEC, Programa Observatório da Educação, coordenada nacionalmente pelos professores Marcos Edgar Bassi (UFPR), Rosana Maria Gemaque Rolim (UFPA) e Maria Dilnéia Espíndola Fernandes (UFMS), por meio de uma bolsa de mestrado.

2 O Estado e Bem-Estar Social, também conhecido como Welfere Satate, foi uma medida inspirada na teoria de Jonh Maynard Keunes, voltada para a reestruturação da economia dos países mais atingidos pela Crise de 1929, que abalou o sistema capitalista. De acordo com a teoria keinesiana, o Estado deveria assumir o papel de protetor e defensor social e, por isso, seria o principal responsável pelo suprimento das necessidades básica da população, preocupando-se com as condições de saúde, trabalho, educação e assistência previdenciária.

3 De acordo com Dutra Júnior. et al. (2000), a LC N. 96/99 estabelece que as despesas com o pessoal ativo, inativo e pensionista dos municípios deverão observar o limite de $60 \%$ da receita líquida, devendo ajustar-se a esse limite, quando em excesso, em até 24 meses, a contar da data de vigência da lei em questão.

4 Ver art. 40 da CF de 1988.

5 Não possui órgão administrador.

6 Substitui a Resolução de no 3, de 1997, do Conselho Nacional de Educação/Câmara da Educação Básica, que orientou a elaboração dos Planos de Carreira à época do Fundef.

\section{Referências}

ANDERSON, Perry. Balanço do neoliberalismo. In: SADER, Emir; GENTILI, Pablo (Org.). PósNeoliberalismo: as políticas sociais e o Estado democrático. 4ª ed. São Paulo: Paz e Terra, 1998; p. 9-28.

ARELARO, Lisete Regina Gomes. FUNDEF: Uma avaliação preliminar dos dez anos de sua implantação. ANPED, 2007. Disponível em:< http://30reuniao.anped.org.br/trabalhos/GT05-3866--Int. pdf> Acesso em: 20 abr. 2016.

BRASIL. Constituição da República Federativa do Brasil: promulgada em 5 de outubro de 1988. Brasília, 1988. Disponível em: <http://www.planalto.gov.br/ccivil_03/constituicao/constituicao.htm>. Acesso em: 08 fev. 2016.

Lei no 9.394, de 20 de dezembro de 1996. Estabelece as diretrizes e bases da educação nacional. Disponível em: <http://www.planalto.gov.br/ccivil_03/leis/19394.htm>. Acesso em: 08 fev. 2016.

Constituição (1988). Emenda Constitucional no 14, de 12 de setembro de 1996. Modifica os arts. 34, 208, 211 e 212 da Constituição Federal e dá nova redação ao art. 60 do Ato das Disposições constitucionais Transitórias. Disponível em: <http://www.planalto.gov.br/ccivil_03/constituicao/ Emendas/Emc/emc14.htm>. Acesso em: 20 fev. 2016.

Constituição (1988). Emenda Constitucional nº 19, de 04 de junho de 1998. Modifica o regime e dispõe sobre princípios e normas de Administração Pública, servidores e agentes públicos, controle de despesas e finanças públicas e custeio de atividades a cargo do Distrito Federal, e dá outras providências. Disponível em: < http://www.planalto.gov.br/ccivil_03/constituicao/emendas/emc/ emc19.htm >. Acesso em: 20 fev. 2016. 
. Constituição (1988). Emenda Constitucional no 20, de 15 de dezembro de 1998. Modifica o sistema de previdência social, estabelece normas de transição e dá outras providências. Disponível em: < http://www.planalto.gov.br/ccivil_03/constituicao/emendas/emc/emc20.htm >. Acesso em: 20 fev. 2016.

. Constituição (1988). Emenda Constitucional no 53, de 19 de dezembro de 2006. Dá nova redação aos arts. 7º 23, 30, 206, 208, 211 e 212 da Constituição Federal e ao art. 60 do Ato das Disposições Constitucionais Transitórias. Brasília, 2006. Disponível em: <http://www.planalto.gov.br/ ccivil_03/constituicao/Emendas/Emc/emc53.htm>. Acesso em: 20 fev. 2016.

. Lei no 9.424, de 24 de dezembro de 1996. Dispõe sobre o Fundo de Manutenção e Desenvolvimento do Ensino Fundamental e Valorização do Magistério, na forma prevista no art. 60, § $7^{\circ}$ do Ato das Disposições Constitucionais Transitórias e dá outras providências. Brasília, 1996. Disponível em: <http://www.planalto.gov.br/ccivil_03/leis/L9424.htm>. Acesso em: 12 fev. 2016.

. Lei n⿳0 11.494, de 20 de junho de 2007. Regulamenta o Fundo de Manutenção e Desenvolvimento da Educação Básica e de Valorização dos Profissionais da Educação - FUNDEB, de que trata o art. 60 do Ato das Disposições Constitucionais Transitórias; altera a Lei N. ํ 10.195, de 14 de fevereiro de 2001; revoga dispositivos das Leis N. 9.424, de 24 de dezembro de 1996, 10.880, de 9 de junho de 2004, e 10.845, de 5 de março de 2004, e dá outras providências. Disponível em: < http://www.planalto.gov.br/ ccivil_03/_ato2007-2010/2007/ Lei/L11494.htm >. Acesso em: 15 fev. 2016.

. Lei n⿳0 11.738, de 16 de julho de 2008. Regulamenta a alínea "e" do inciso III do caput do art. 60 do Ato das Disposições Constitucionais Transitórias, para instituir o piso salarial profissional nacional para os profissionais do magistério público da educação básica. Brasília, 2008. Disponível em: <http:// www.planalto.gov.br/ccivil_03/_ato2007-2010/2008/lei/111738.htm >. Acesso em: 15 fev. 2016.

. Ministério da Educação. Conselho Nacional de Educação. Resolução CNE/CEB nº 2, de 28 de maio de 2009. Fixa as Diretrizes Nacionais para os Planos de Carreira e Remuneração dos Profissionais do Magistério da Educação Básica Pública. Disponível em: <http://portal.mec.gov.br/dmdocuments/ resolucao_cne_ceb002_2009.pdf $>$ Acesso em: 10 fev. 2016.

. Ministério da Educação. Conselho Nacional de Educação. Resolução CNE/CEB no 3, de 8 de outubro de 1997. Fixa as Diretrizes para Novos planos de Carreira e de Remuneração para o Magistério dos Estados, do Distrito Federal e dos Municípios. Disponível em: < http://portal.mec.gov. br/cne/arquivos/pdf/CEB0397.pdf> Acesso em: 10 fev. 2016.

BRESSER-PEREIRA, L.C. Plano Diretor da Reforma do Aparelho do Estado. Brasília, 1995. Disponível em: < http://www.bresserpereira.org.br/documents/mare/planodiretor/planodiretor.pdf > Acesso em: 12 abr. 2016.

DINIZ, Eli. O Contexto Internacional e a Retomada do Debate sobre Desenvolvimento no Brasil Contemporâneo (2000/2010). In: DADOS - Revista de Ciências Sociais. Rio de Janeiro, vol.54, nº 4, 2011, p. 493 - 531.

DUTRA JÚNIOR. Adhemar F. et al. Plano de carreira e remuneração do Magistério Público: LDB, FUNDEF, diretrizes nacionais e nova concepção de carreira. Brasília: MEC, FUNDESCOLA, 2000. 234 p.

ESPÍNOLA. Viola. Comentários. In: Equidade e Financiamento da Educação na América Latina. Brasília: UNESCO, IIPE - Buenos Aires, 2002.

GEMAQUE, Rosana Maria Oliveira. Relatório do Estágio Pós-Doutoral. Universidade de São Paulo, São Paulo, 2013.

. Rosana Maria Oliveira. Financiamento da educação, o FUNDEF no Estado do Pará: feitos e fetiches. 2004. 372 f. Tese (Doutorado em Educação) - Faculdade de Educação, Universidade de São Paulo, São Paulo, 2004. 
OLIVEIRA, Romualdo Portela de. O financiamento da Educação. In: OLIVEIRA, Romualdo Portela de; ADRIÃO, Teresa (Orgs). Gestão, financiamento e direito à educação. $3^{\circ}$ ed. São Paulo: Xamã, 2007.

PICANÇO, Bruno Cordovil. A Regulação do Estado na Educação Básica por meio da Política de Fundos (FUNDEF e FUNDEB). 2012. 173 f. Dissertação (Mestrado em Educação) - Programa de PósGraduação em Educação, Universidade Federal do Pará, Belém, 2012.

SAVIANI, Dermeval. Da nova LDB ao FUNDEB: por uma outra política educacional. $4^{a}$ ed. Campinas, SP: Autores Associados, 2011.

VIEIRA, Juçara Dutra. Piso salarial para os educadores brasileiros: quem toma partido? Campinas, SP: Autores Associados, 2013. 


\section{$\mathrm{BE}^{*}$ and the Public magisterium In the light of state reform}

ABSTRACT: The article reveals that the regulation of the career of public school teachers in basic education, which has been inserted into the reform plan, has followed the neoliberal formula of introducing different regulatory mechanisms, and is one of the obstacles to the development of career plans committed to the valuing of the teacher.

Keywords: Regulation. Career of public basic education teachers. State reform.

* Basic Education

\section{Enseignement public de 1'EB* À la lumière de la réforme de l'Etat}

RÉSUMÉ: L'article révéle que la réglementation de la carrière de l'enseignement public de l'éducation basique était intégrée au le plan de réforme, lequel, pour avoir suivi le modéle néo-libéral, a introduit différents mécanismes de régulation, un des obstacles à l'élaboration de plans de carrière engagés pour la valorisation des enseignants.

Mots-clés: Réglementation. Carrière de l'enseignement public de l'éducation basique. Réforme de l'Etat.

* Éducation Basique

\section{Magisterio público de la EB* A la luz de la reforma del Estado}

RESUMEN: El artículo muestra que la reglamentación de la carrera del magisterio público de la educación básica estaba incluida en el plan de reforma que, al haber seguido la receta neoliberal, introdujo diferentes mecanismos reguladores, uno de los obstáculos para la elaboración de planes de carrera comprometidos con la valoración docente.

Palabras clave: Reglamentación. Carrera del magisterio público de la educación básica. Reforma del Estado.

* Educação Básica 